\title{
Improving Young Leaners' English Listening Skill through the Use of Audio Slide Show on elllo.org
}

\author{
Fatimah $^{\mathrm{a}, 1}$ \\ ${ }^{\mathrm{a}}$ Semarang State University, Semarang, Indonesia \\ ${ }^{1}$ fatimah_tamy@yahoo.com
}

\begin{abstract}
Young learners as future leaders need to master English as an international language. The development of technology also needs to be mastered. In addition, the first skill that has to be mastered for learning language is listening. A website called www.elllo.org provides some interesting audio slide shows for helping learners improving their listening skill. This paper aimed to find out the possibility of using audio slide show on www.elllo.org and its impacts for improving young learners' listening skill and also describe its strengths and weaknesses. By conducting this, we find out that this site provide authentic materials by interactive and attractive media. In addition, the material is easy and free to be downloaded and provides level for learners to get materials they need. At the end of the learning process, there are some quizzes that may be used to measure learners' understanding of the materials. This website can also be accessed anytime and anywhere with the student-centered approach in materials. However, by using this kind of method, sometimes the internet connection is not easy to be gotten; blackout or low battery may also block this kind of learning method. As a suggestion, the website developers of www.elllo.org may give more various authentic materials for enriching learners' knowledge of English and the speaker in the video may produce louder voice to make it easier to be heard.
\end{abstract}

Index Terms - www.elllo.org, audio slide show, listening skill, young learners

\section{Introduction}

In this global era, people have to master English, as the international language, well. Parents also want their children to master English from very young age since they think that children are in golden age, so they have to learn many things to enrich their knowledge including the linguistic side like mastering second or foreign language. Parents do some strategies to make it happens such as: entering their children to an international kindergarten, or entering them to a private course so that their children will master English well as soon as possible. Children who learn English since young age are called as "young learners".

It should be emphasized that the purpose of teaching language for young learners in Indonesia is languageaccompanying action. As a result, teachers should know the best method to teach them because learners' mood has changed quickly; but, their interest to know something new is very high. Besides, since they are in young age, learners love to do any activities in fun ways, even when they are studying.

The development of technology gives some impacts of teaching-learning process of English for young learners. One of the most popular methods of using technology for teaching-learning English is through the use of web-based learning. It is an application of computer and internet developing for administering and conducting learning activity by using internet as the source of material, online course, online assignment and test [4]. There are a lot of online listening-based learning websites for helping young learners improve their listening skill; however, this paper will focus on the audio slide show on www.elllo.org website as the subject media since all the materials provided in this site are free and easy to be downloaded. In addition, the audio slide shows on this site are attractive so it can improve learners' enthusiasm of improving their listening skill. This paper investigates the use of audio slide shows on www.elllo.org for improving young learners' listening skill, including its benefits, strengths and weaknesses, and also the advantages of using this site for improving their listening skill.

This paper is written for finding out the possibility of using audio slide show on www.elllo.org and its impacts for improving young learners' listening skill. In addition, it is also for describing the strengths and weaknesses of using "Audio Slide Show" on www.elllo.org for improving listening skill of young learners.

\section{Literature Review}

A. Listening

Listening is the first stage that has to be mastered for everyone to learn everything, including learning language. So, the achievement of mastering listening skill will help learners developing other language skills, such as: speaking, reading, and writing. Listening is not only the process of hearing what the speaker says, but also understanding the meaning of what is said. The differences between them are during listening process, the hearer has willingness and competence to understand what is said, however, during hearing process, ones just hear what is said; they do not need to understand the meaning of it. Reference [2] argues that the differences of listening and hearing are in terms of a degree of intention; listening is a mental process of constructing meaning from spoken input, while hearing is physiological system that allows for reception and conversation of sound waves that surround the hearer. Listening involves more than just hearing or paying attention. So, it is clear that listening is an active skill that requires an active attention and intention of the hearer.

After having clear explanation of the differences between hearing and listening, it is important to know the process of listening itself. Reference [2] defines listening is a process of receiving what the speaker actually says (receptive orientation); constructing and representing meaning (constructive orientation); negotiating meaning with the speaker and responding (collaborative orientation); 
and, creating meaning through involvement, imagination and empathy (transformative orientation). Reference [2] states "listening, especially for academic and professional contexts, is a highly refined skill that requires a learner's attention to a battery of strategies for extracting meaning from texts." So, improving listening is the most important thing in communication because if learners understand what the speaker says, the communication will run communicatively. In addition, effective listening requires active and conscious attention to the sounds to gain their meaning.

\section{B. Young Learners}

Reference [9] defines "young learners here are those who at the age of four until fourteen." In this early age, it will be useful to teach them new language since they are in golden age. Reference [3] states "young children can learn a second language particularly before puberty because their brains are still able to use the mechanism that assisted first language acquisition".

Besides, it should be remembered that the purpose of teaching new language for young learners is languageaccompanying action. They are taught to get language knowledge and skill. "The aim of Teaching English to Young Learners (TEYL) is to provide you with knowledge and skills for teaching English as a second or foreign language to young learners" [5].

Young learners love to be taught in fun ways, this is the teacher's duty to make variation in technique of teaching so that young learners will enjoy learning language and they will not feel boring in the learning process; this usually called learning by playing according to Ref. [9] "by "playing" with the language children make it their own."

From the definitions above, it can be concluded that young learners are children who are at the golden age (4-14 year-old); in this age, learners tend to learn something in fun ways. Actually language should be taught to young learners accompanying by actions (language accompanying action) so that they exactly understand the meaning behind the words/instructions given.

\section{Web-based learning}

Nowadays, the rapid grown of technology makes people that are working in education field need to be more creative to build up innovation in the teaching learning process so that learners will be more enthusiastic and interested in the teaching learning process. There are a lot of innovative approaches in language learning that can be used for teaching English to ESL/Young learners. This paper will focus on one of that popular approach that is called as webbased learning. Relan \& Gillami (1997) in Ref. [6] defines web-based learning as "the application of a repertoire of cognitively oriented instructional strategies with a constructivist and collaborative language learning environment, utilizing the attributes and resources of the World Wide Web." Reference [4] also states that web-based learning is teaching learning practice using internet or World Wide Web for transferring knowledge, giving and assessing assignments and works, giving exams, discussion forum, giving lecture, etc. From those definitions, web-based learning is actually a learning of content of language via World Wide Web.

The easy access of web-based learning makes this approach become more and more popular for Young learners. They can access every websites they need easily by connecting it through the internet and find their own materials so they will be happy learn what they want. This approach is using learners-centered approach rather that teacher-centered approach since learners are encouraged to learn language by themselves and are motivated to continue in the growth of their own learning when connected to others [6]. Learners are more independent for choosing what they want to learn to improve their English.

Besides, the easy access of web-based learning also brings another benefit in the part of materials that learners needs. The web-based learning also provides accessibility and availability of authentic materials [6]. Authentic materials are useful for learners to learn language in the real context so that they can imagine how to use that language in the real life situation.

In addition, using web-based learning can make the learning materials more interesting and attractive since it is possible to insert pictures, audio, videos, chat rooms, and webcasts in the materials. Reference [6] argues that "webbased learning supports a constructivist model of learning, where students can become more interactive and more involved in their own learning, thereby constructing their own knowledge." The interactive media that web-based learning provides is really helpful for attracting learners to the content of learning.

\section{Audio Slide Show of www.elllo.org}

ELLLO, which stands for English Language Listening Lab Online, is a web-based learning site that has over 1,000 collections of listening activities that can be viewed freely via internet. According to Ref. [7] in http://teslej.org/ej31/m1.html, English Language Listening Lab Online (ELLLO) is an interactive self-study website that provides audio interviews and supplementary materials that consist of authentic dialogues with English speakers and different interviews for the improvement of learners' listening skills. The listening materials here can be downloaded in the format of MP3 audio file. It also contains the transcription and provides interactive quizzes. The listening materials in ELLLO sites have specific targets for fulfilling the learners' interest and needs for learning English. One of the features here is Audio Slide Show, an online, multimedia listening website designed by Ref. [1] that can be used to help those who want to learn English, especially listening, online. The website www.elllo.org offers vary types of listening media such as: videos, pictures, and audio slide shows themselves. This website is really a helpful media either for the teacher to build their media in teaching English or for the learners who want to learn listening by themselves.

Audio slide shows of www.elllo.org are one type of media provided by Ref. [1] in this website. It uses a flash player and some pictures to play the audio and transcript of the monologue to make learners easy to understand the audio files. The audio files content of some audios with different topic. He created this site in his free time and tried to share 
his belief for helping young learners improving their listening skill by becoming more often listening to English for enjoyment or intrigue in their daily life.

From the explanation above, it is clear that www.elllo.org is a good alternative in giving innovation teaching learning practices in listening for young learners so that they will be faster on understanding someone's utterances and more enthusiastic in learning English. This will make them become a better communicator of using English.

\section{Findings and Discussion}

As it has been mentioned above, internet provides some facilities that may interest young learners for learning some materials, such as: using sounds, catchy games, and also audiovisual media. Some pages are provided to serve the need of young learners' e-learning media, such as: kidspages.com, elllo.org, e-learningforkids.org, and etc. These pages provide many useful and interesting media for young learners to learn. www.elllo.org makes their listening learning process becomes more fun and interesting. Here are some analysis of the benefit and obstacles that sometimes happen when young learners learn through this website.

\section{A. Benefits of learning listening by using www.elllo.org for Young Learners}

There are a lot of impacts that www.elllo.org website offer for improving young learners listening skill, especially through its audio slide show. Some benefits of using www.elllo.org for improving young learners' listening skill can be seen in the following:

1. Providing authentic materials for preparing learners in the real life situation by using language. It means that when learners use English in their daily life, they will be more familiar with the language and have deeper knowledge about it,

2. Attractive and innovative materials for attracting learners learn the new materials. This is so important for material developers to attract learners to the materials. www.elllo.org has excellent sources for materials as well as the way of delivering it, the materials are attractive, innovative, and easily to be understood,

3. Easy downloading materials. It is important for learners to learn outside the classroom, they may access this website to improve their listening skill. However, this website also provide easy download for the materials given so that learners can still re-listen to the materials even they do not have internet connection or they may use them just for daily practice,

4. Free access as long as we have internet connection. Learners do not need to pay anything for accessing this website as long as they have internet connection, so using this website is easy and cheap,

5. Providing level for learners to get materials they need. www.elllo.org provides level of learning materials, so learners can get their own needs of the materials based on their level of learning English. This brings many benefits since for example, beginner level learners can access some listening materials for their level; they will not get confused for choosing the appropriate materials for improving their skills,

6. Providing games so that learners will not get bored in the study time. The games here is educated games for helping learners improving their English skills in fun ways and will not make them bored with the materials given,

7. Providing audio slide show for enhancing students' enthusiasm. By using slide show learners can learn the expression of what the speaker says, they can identify the appropriate time and expression for using something,

8. Providing dialogues of people's from other countries so that learners will also learn about other culture. Learning about other culture is very important for opening learners' mind about other way of life,

9. Providing transcription so that learners will easily learn the words that are used in the dialogue directly. Transcription is very helpful for learners to see the words correctly and for some visual learners; it will help them understand the words deeper, and

10. Providing interactive quizzes to check learners' understanding about what they hear. Interactive quizzes are really helpful since learners will not feel scary for taking the quizzes; and they will get their score directly.

\section{Strengths and weaknesses}

Using web-based learning of www.elllo.org has some strengths and weaknesses for the teaching learning process, they are:

\section{A. Strengths:}

a. Easy connection to the external sources of materials for improving learners' knowledge,

b. Easy update content; so, the materials will be easily updated everyday.

c. Easy connection with other students across countries,

d. It can be access anytime, anywhere,

e. Student-centered approach,

f. Creative teaching for attracting learners' attention to the materials.

\section{B. Weaknesses}

Every strength has their own weaknesses and in this approach, the weaknesses are:

a. Limitation of the technology; some learners do not have internet connection to get the materials in www.elllo.org site,

b. Blackout is sometimes become an unexpected situation for getting the materials in this website,

c. Looking for the appropriate materials. Since some learners still new in learning English, it will not be easy for them to choose the materials for them,

d. Chance for cheating. When learners do their quizzes, it will be easier for them to see the transcription provided in this site to get the correct answer for the questions given,

\section{Advantages}

The advantages of web-based learning with 
www.elllo.org for improving listening skill of young learners are:

a. The flexibility of time and place for accessing this site,

b. Using authentic materials for Young learners' understanding,

c. Easy for structuring information,

d. Opening learners' mind through the real world situation,

e. Giving some knowledge of other culture,

f. Interactive quizzes for checking learners' understanding,

g. Giving some expressions for interacting with other people,

h. Independency in learning,

i. Free for accessing the materials, and

j. Easy to operate the materials.

\section{Conclusions and Suggestion}

Learning English nowadays is easier since there are some websites providing web-based learning freely to young learners. www.elllo.org is one of the prominent website that provides free access of listening materials for young learners and has audio slide show to make learners attract in the materials given. As listening is the first skill that need to be mastered by young learners for learning language, this website provides appropriate materials of listening to help learners improving their listening skills. This website offers audio slide show as the media that can improve learners' listening skill in English and also provides some activities that help them achieving this goal. Each listening activity has an audio, including a picture and script in that presentation. The media is an online, sophisticated media in teaching and learning process; this website also has some quizzes for checking learners understanding.

There are some challenges for improving this website to reach its goal helping Young learners improve their listening skill. As a suggestion, I would like to ask for fixing some error video links in some videos in this site, I also want to suggest for fixing some uncompleted video here since it will be awkward for listeners to hear only some part of the video, learners will be curious to know what is the next part of the conversation of this video. It is also recommended to present new feature of showing the audio slide show through full screen video so that learners will be clearer in watching the video. Besides, the speaker on the dialogue of the videos in this side may speak louder so that their voice can be heard clearly. Improving learners' skill in computer literacy is also very important so that they can utilize and maximize using this website for improving their listening skill. Last but not least, I may suggest the website developers of www.elllo.org for giving more various authentic materials for enriching learners' knowledge of English.

\section{References}

[1] T. Beuckens, "Talking points," Kyusyu, 2004. www.elllo.org (accessed 7/3/2013)

[2] H. D. Brown, Teaching by Principles. Second edition. Englewood Cliffs: Prentice Hall Regents, 2001.

[3] L. Cameron, Teaching Languages to Young Learner, Edinburgh: Cambridge University Press, 2001.

[4] Hartoyo, ICT in Language Learning, Semarang: Pelita Insani
Semarang, 2012.

[5] D. Nunan, Teaching English to Young Learners, Anaheim: Anaheim University Press, 2011.

[6] A. Q. Pacheco, "Web-based learning (wbl): A challenge for foreign language teachers," Revista Electrónica Actualidades Investigativas en Educación, vol. 5, no. 2, pp. 1-25, 2005.

[7] L. Piasetski, "English Language Listening Lab Online: Web site review," Available at http://tesl-ej.org/ej31/m1.html (access on 3/6/2013)

[8] M. Rost, Teaching and Researching Listening, London, UK: Longman, 2002.

[9] A. Wright, Creating Stories with Children, New York: Oxford University Press, 1997. 